\title{
A Model of Translator's Competence from an Educational Perspective
}

\author{
Oktay Eser \\ Amasya University \\ Amasya, 05100, Turkey
}

Received: $15-12-2014$

doi:10.7575/aiac.ijclts.v.3n.1p.4
Accepted: 18-12- 2014

Published: 01-01- 2015

\begin{abstract}
Translation as a business is a service. The concept of translation competence is a term covering the various skills and knowledge that a translator needs to have in order to translate functionally. The term which is often studied as a multicomponential concept in literature may not cover the necessary skills if it is taken from an organizational point of view. Program designs at the departments of Translation Studies at universities can be seen as a model for students to acquire translation competence. One of the primary purposes of translation education is to measure and assess the acquisition of translation competence. Despite the fact that the concept of translation competence consists of knowledge and skills needed to translate, the job description of a translator in the translation sector may well go beyond the proper translation process from an organizational perspective. This study focuses on the need for a change from translation competence to translator's competence. The need was observed through a scale of translation competence conducted at the states universities in Turkey, which resulted in the proposed model of translator's competence. A scale of translation competence concerning student perceptions was used as an empirical data collection tool in quantitative research in Translation Studies, the reliability statistics of which was tested as ,951 with 448 participants. The scale consists of 50 statements and measures 8 sub-competencies. This paper proposes a model of translator's competence from an educational perspective, thus paving the way for more effective translator education required to meet the expectations in the translation sector. The concept of translator's competence was proposed as an umbrella term to cover the needs of translation business. It is based on the three different skills of technical skills, conceptual skills and interpersonal skills in which the technical skills represent the translation competence as one of the constituents of the translator's competence. Program designs at tertiary education can be more effective in that it takes this aspect into consideration.
\end{abstract}

Keywords: Translator's competence, translation competence, translation education, translator training, translation sector, translation companies

\section{Introduction}

Translation as a business is a service. This paper proposes a model of translator's competence from an educational perspective, thus paving the way for more effective translator education required to meet the expectations in the translation sector. The concept of translation competence is a term covering the various skills and knowledge that a translator needs to have in order to translate functionally. The term which is often studied as a multi-componential concept in literature may not cover the necessary skills if it is taken from an organizational point of view. Program designs at the departments of Translation Studies at universities can be seen as a model for students to acquire translation competence. One of the primary purposes of translation education is to measure and assess the acquisition of translation competence. The concept of translator's competence was proposed as an umbrella term to cover the needs of translation business. A scale of translation competence concerning student perceptions was used as an empirical data collection tool in quantitative research in Translation Studies, the reliability statistics of which was tested as ,951 with 448 participants. The scale consists of 50 statements and measures 8 sub-competencies.

\section{Literature Review}

Competence is a multi-disciplinary concept. Many other words such as ability, skill, qualification, effectiveness, efficiency and proficiency have been used instead of the concept of comptence to describe an individual as well as behaviour over time (Weinert, 1999:4). Competence is studied in some various disciplines. Psychology deals with it as it involves motivation and values. Educational sciences look at the concept as one the governing terms for program designs. Sociology is another field in which competence appears as it treats of the concepts of social norms and responsibility.

In the article entitled "Understanding the Concept of eCompetence for Academic Staff", Schneckenberg and Wildt investigates the fundamental constituents of the concept of competence. It is never confined to developing some certain skills pertaining to a profession or craft. It is the ability to effectively cope with difficulties in a situation and is seen in a performance (Schneckenberg ve Wildt, 2006:30). In the acquisition of competence, there are steps related to each other. Each step is built upon the other. Schneckenberg ve Wildt show these steps to the acquisition of competence as in the Figure 1 below (Schneckenberg ve Wildt, 2006:31). 
At the beginning is information. Through networking, it turns into knowledge. It is an ability if knowledge is applied in a given situation. When an ability is mixed with attitude consisting of motivation and values, an action is mentioned. Competence is when an action meets the criteria of adequateness to social norms. Professionalisation is the last step where competence comes with responsibility.

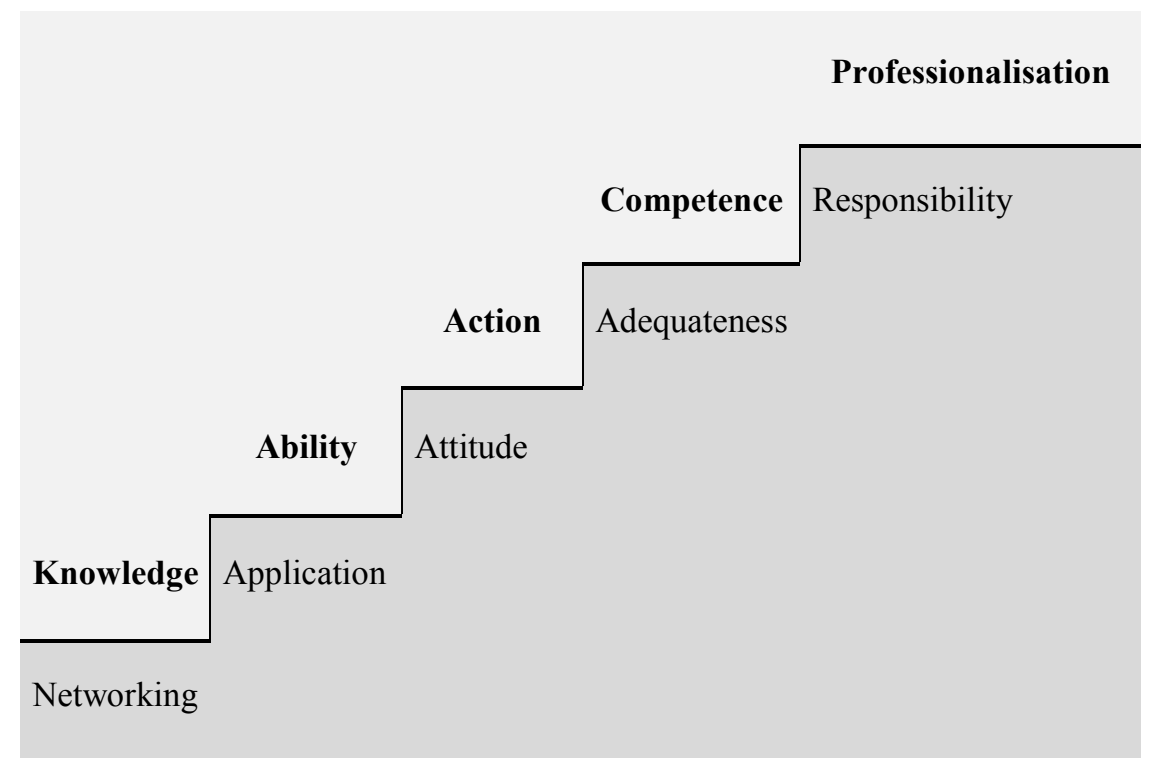

Figure 1. Steps to the Acquisition of Competence

Source: Schneckenberg ve Wildt, Understanding the Concept of eCompetence for Academic Staff, 2006:31.

Another comprehensive study of the concept of Competence is the DeSeCo (Definition and Selection of Competencies: Theoratical and Conceptual Foundations) Project initiated in 1997. It aims to define competence andto determine the basic key-competencies related to the socio-economic environment (DeSeCo, 2001:2). They study it as an action-oriented concept of cognitive and incognitive constituents. It can't be free from an action. It is goaloriented and appears in a situation. Therefore, it is social. Rychen defines competence(Rychen, 2003:3):

"A competence is defined as the ability to successfully meet complex demands in a particular context through the mobilisation of knowledge, cognitive skills but also practical skills, as well as social and behaviour components such as attitudes, emotions, and values and motivations."

Competence is a determining factor in drawing up program designs in education. In a learner-centered approach, there are some dichotomies standing out: Goal- vs. competence-orientedness, behavourism vs. social constructivism, teaching vs. learning, information vs. situaltion (Jonnaert et. al., 2006:13).

Competence-oriented program designs have been around for the department of Translation and Interpreting at university. Such concepts as knowledge (PACTE, 2000; Bell, 1991; Tirkkonen-Condit, 1992), skills (Harris and Sherwood, 1978; PACTE, 2000), ability (Koller, 1979; Toury, 1984; Bell, 1991), expertise (Kiraly, 2003; Shreve, 2002), and proficiency (Wilss, 1992; Cao, 1996; Malmkjaer, 2008) define the qualities that a translator needs to have in order to translate texts. These qualities fullfil seperate but complementary needs in the translation competence, which is an umbrella term involving them all. Recent research has shown that translation competence has been evolving from partial research to holistic and empirical models. The models of translation competence which study the concept as a multi-componential term often divides into two: Models resulting from the needs of translation education and those of translation sector.

On translation education, there are models of translation competence drawn up by such individual researchers as Neubert (Neubert, 2000:3), Schäffner (Schäffner, 2000:146-148), and Yazic1 (Yaz1c1, 2007:139) and research projects like PACTE (Process in theAcquisition of Translation Competence and Evaluation) carried out at UniversitatAutonoma de Barcelona (PACTE, 2003:60) and TransComp at UniversitätGraz (Göpferich, 2009:21). They aim to study and improve the concept of translation competence and competence-based program designs.

As of translation sector, there are two research projects which stand out. EMT (European Master's in Translation) Project is funded by the European Commission (EMT, 2009:3) and the European Quality Standard for Translation services: EN-15038 (CEN, 2006:6-7) Project is a Project in the European Union. These are the type of projects which aim to ensure translation services of quality in order to meet the needs of the translation sector in a multilingual/cultural environment in the European Union. As a project which proposes a model of translation competence, PACTE defines translation competence as:

"Translation competence is defined as the underlying system of knowledge and skills needed to be able to translate." (PACTE, 2000:100; PACTE, 2003:58; PACTE, 2011:33) 
The model is made up of a set of sub-competencies that are inter-related and hierarchic, with the strategic subcompetence occupying a dominant position.

$$
\begin{aligned}
& \text { - bilingual sub-competence } \\
& \text { - extra-linguistic sub-competence } \\
& \text { - knowledge about translation sub-competence } \\
& \text { - instrumental sub-competence } \\
& \text { - strategic sub-competence } \\
& \text { - psycho-physiological components }
\end{aligned}
$$

In the model, the bilingual sub-competence is made up of pragmatic, socio-linguistic, textual and lexical-grammatical knowledge in each language. The extra-linguistic sub-competence is made up of encyclopaedic, thematic and bicultural knowledge. The knowledge about translation sub-competence is knowledge of the principles that guide translation (processes, methods and procedures, etc.) and the profession (types of translation briefs, users, etc.). The instrumental sub-competence is made up of knowledge related to the use of documentation sources and information technologies applied to translation. The strategic sub-competence is the most important, as it is responsible for solving problems and the efficiency of the process. It intervenes by planning the process in relation to the translation project, evaluating the process and partial results obtained, activating the different sub-competencies and compensating for deficiencies, identifying translation problems and applying procedures to solve them. The psycho-physiological components are cognitive and behavioural (memory, attention span, perseverance, critical mind, etc.) and psychomotor mechanisms (PACTE, 2005:610). Any bilingual has knowledge of two languages and may have extralinguistic knowledge, we consider that the sub-competencies specific to TC are the strategic, the instrumental and knowledge about translation (PACTE, 2005:611; Albir, 2010:57; PACTE, 2011:34). In his work entitled "Assessment of the Concept of Competence in Translation Education", Eser shows these models in a matrix. He points out that there are 14 different sub-competencies which overlap or contradict with each other (Eser, 2013:63-64).

\subsection{Findings about the Models of Translation Competence}

In the models of translation competence, we have found 14 different kinds of sub-competencies. Drawing on these subcompetencies, we can arrive at some descriptive results as shown below:

1- Translation competence is qualitatively different from bilingual competence. It is not just an advanved command of linguistic competence. Bilingual competence is one of the sub-competences that make up translation competence.

2- The definition of the sub-competences peculiar to translation competence differentiates translation phenomenon from such adjacent areas as languistics and literature.

3- Translation competence is a multi-componential concept and is made up of a system of sub-competencies that are inter-related, hierarchical and that these relationships are subject to variations. Translation competence is the underlying system of knowledge needed to translate.

4- Translation competence is a term governing translation didactics. Competence-based program designs are considered to bplay an important part in the acquisition of translation competence.

5- Translation competence earns translators a meta-language.

6- The models of translation competence embrace holistic and dynamic approach towards translation competence. They take translation phenomenon as a whole and are adjust themselves to meet the needs that arise over time.

7- The models of translation competence are empirical and objective.

8- Research into translation competence attempts to respond to the needs of translation didactics as well as translation sector.

9- The concept of translation competence has been a determining factor in setting translation service standards, which may contribute to the professionalization of translation.

10- Behavioural research is observable in drawing up the models of translation competence in that the concept is dismantled into smaller sub-competences which, in turn, make up translation competence.

\section{Methodology of the Research}

\subsection{Objectives and Restrictions of the Research}

The main objective of the reseach is to describe the acquisition of the sub-competencies of translation quantitatively and to relate them to the translation business in a way to propose a model of translator's competence from an educational perspective. In consolidating the model, I will also look at such mangerial skills as conceptual skills and interpersonal skills to see if they play a role in the design of the model.

\subsection{Variables of the Research}

Variables relating to the career expectations as a demographic variable, and the sub-competencies of translation competence were used as in the following.

\section{Demographic variables:}

- Career expectations 
Variables relating to translation competence:

- Bi-lingual sub-competence,

- Cultural sub-competence,

- Domain/Thematic sub-competence,

- Textual sub-competence,

- Research and technological sub-competence,

- Strategic sub-competence,

- Knowledge about tranlation sub-competence,

- Translation service provision sub-competence.

\subsection{Universe and Sampling}

The universe of the research is the final-year students of Translation and Interpreting at state universities in Turkey due to time and money restrictions. Convenience sampling was preferred. Data collection was conducted during the 20112012 academic year. 448 valid questionnaires were returned. The universe of the research was about 750 students from 9 state universities across Turkey. With a gender ratio of 80\%-20\% (336 female and 112 male participants), 185 questionaires would be sufficient for the research to be valid.

\subsection{Data Collection Tool and Analysis of the Data}

The questionaire consisted of two parts: Demographic information and sub-competencies of translation. The subcompetencies of translation had 50 statements which fell into 8 categories indicating the sub-competencies mentioned above. The data collected in the research was analysed on the SPSS Statistics 17.0.

\section{Results}

Below are the results from the scale of translation competence found in Appendix $1 \& 2$.

Table 1. Percentage of Students by Career Expectations

\begin{tabular}{|c|c|c|c|c|}
\hline \multicolumn{2}{|r|}{$\begin{array}{c}\text { Career Expectations } \\
\text { I want to... }\end{array}$} & Frequency & Per cent & $\begin{array}{l}\text { Cumulative } \\
\text { per cent }\end{array}$ \\
\hline \multirow{7}{*}{ : } & be a translator & 148 & 33,0 & 33,0 \\
\hline & set up a translation business & 15 & 3,3 & 36,4 \\
\hline & be an academician & 80 & 17,9 & 54,2 \\
\hline & be an editor & 29 & 6,5 & 60,7 \\
\hline & work in another sector & 142 & 31,7 & 92,4 \\
\hline & other & 34 & 7,6 & 100,0 \\
\hline & Total & 448 & 100,0 & \\
\hline
\end{tabular}

The percentage of students by career expectations are as follows: Those who want to be a translator represent $33 \%$ of all the participants, $31,7 \%$ of whom prefer working in another sector other than translation. $17,9 \%$ of them want to be an academician. Those who have other options represent 7,6\%. 6,5\% of them want to be an editor. Those interested in setting up a translation business account for $3,3 \%$ only.

Table 2. Distribution of Means by Translation Sub-competencies

\begin{tabular}{lrr}
\hline \multicolumn{1}{c}{ Translation sub-competencies } & Means & $\begin{array}{c}\text { Standard } \\
\text { Deviation }\end{array}$ \\
\hline Bi-lingual sub-competence & 3,91 &, 63397 \\
Cultural sub-competence & 3,63 &, 63630 \\
Domain/Thematic sub-competence & 3,64 &, 69255 \\
Textual sub-competence & 3,84 &, 60685 \\
Research and technological sub-competence & 3,73 &, 59353 \\
Strategic sub-competence & 3,66 &, 62883 \\
Knowledge about translation sub-competence & 3,47 &, 70541 \\
Translation service provision sub-competence & 3,70 &, 60162 \\
\hline
\end{tabular}


The distribution of means by translation sub-competencies indicate that bi-lingual sub-competence has the highest value with a percentage of 3,91. The textual sub-competence accounts for 3,84\% while research and technological subcompetence account for $3,73 \%$. The translation service provision sub-competence has a percentage of 3,70. Strategic sub-competence is $3,66 \%$. The domain/thematic sub-competence and cultural sub-competence are with 3,64\% and $3,63 \%$ respectively. The knowledge about translation sub-competence has the lowest percentage with 3,47\%.

\subsection{Correlation Analysis}

Dependence is any statistical relationship between two random variables or two sets of data. Correlation refers to any of a broad class of statistical relationships involving dependence. It is a term that refers to the strength of a relationship between two variables. The correlation coefficient is a measure of linear association between two variables. Values of the correlation coefficient are always between -1 and +1 . A correlation coefficient of +1 indicates that two variables are perfectly related in a positive linear sense, a correlation coefficient of -1 indicates that two variables are perfectly related in a negative linear sense, and a correlation coefficient of 0 indicates that there is no linear relationship between the two variables. The most widely used type of correlation coefficient is the Pearson $r$, measuring the degree of correlation. Rank correlation coefficients, such as Spearman's rank correlation coefficient and Kendall's rank correlation coefficient $(\tau)$ measure the extent to which, as one variable increases, the other variable tends to increase, without requiring that increase to be represented by a linear relationship. To decide whether to reject the null hypothesis that the variables are uncorrelated, we compare the p-values against 0.05 . The Kendall rank coefficient is often used as a test statistic in a statistical hypothesis test to establish whether two variables may be regarded as statistically dependent. This test is non-parametric, as it does not rely on any assumptions on the distributions of $X$ or $Y$ or the distribution of $(X, Y)$ (Eymen, 2007:87-109).

The scale used to collect data is an ordinal scale. The relationships between two ordinal variables can be measured through Kendall's tau-b test. Here, the relationships between the sub-competencies of translation and the career expectations were measured.

Table 3. Relationship between Bi-lingual Sub-competence and Career Expectations

\begin{tabular}{lllr}
\hline \multicolumn{3}{c}{ Bi-lingual sub-competence correlations } \\
\hline & & \multicolumn{2}{c}{ Career } \\
Expectations \\
Kendall's & Bi-lingual sub- & Correlation &,- 034 \\
tau_b & competence & Coefficent &, 355 \\
& & Sig. (2-tailed) & 448 \\
\hline
\end{tabular}

A p-value of ,355 was found. Even though a correlation coefficient of -,034 indicates that two variables are related in a negative linear sense, the variables are uncorrelated. The null hypothesis is rejected.

Table 4. Relationship between Cultural Sub-competence and Career Expectations

\begin{tabular}{lllr}
\hline \multicolumn{3}{c}{ Cultural Sub-competence correlations } \\
\hline & & \multicolumn{2}{c}{ Career } \\
Kendall's & Cultural Sub- & Correlation &,- 100 \\
tau_b & competence & Coefficent &, 007 \\
& & Sig. (2-tailed) & 446 \\
& & $\mathrm{~N}$ & 4 \\
\hline
\end{tabular}

A p-value of ,007 was found. A correlation coefficient of -,100 indicates that two variables are related in a negative linear sense and the null hypothesis is accepted.

Table 5. Relationship between Domain/Thematic Sub-competence and Career Expectations

\begin{tabular}{lllr}
\hline \multicolumn{3}{c}{ Domain/Thematic Sub-competence correlations } \\
\hline & & \multicolumn{2}{c}{ Career } \\
Kendall's & Domain/Thematic & Correlation &,- 118 \\
tau_b & Sub-competence & Coefficent &, 002 \\
& & Sig. (2-tailed) & 444 \\
& & $\mathrm{~N}$ & 4 \\
\hline
\end{tabular}


A p-value of , 002 was found. A correlation coefficient of -,118 indicates that two variables are related in a negative linear sense and the null hypothesis is accepted.

Table 6. Relationship between Textual Sub-competence and Career Expectations

\begin{tabular}{lllr}
\hline \multicolumn{3}{c}{ Textual Sub-competence correlations } \\
\hline & & \multicolumn{2}{c}{$\begin{array}{c}\text { Career } \\
\text { Expectations }\end{array}$} \\
Kendall's & Textual Sub- & Correlation &,- 118 \\
tau_b & competence & Coefficent &, 001 \\
& & Sig. (2-tailed) & 446 \\
& & $\mathrm{~N}$ & 4 \\
\hline
\end{tabular}

A p-value of ,001 was found. A correlation coefficient of -,118 indicates that two variables are related in a negative linear sense and the null hypothesis is accepted.

Table 7. Relationship between Research and Technological Sub-competence and Career Expectations

\begin{tabular}{lllr}
\hline & Research and Technological Sub-competence correlations \\
\hline & & \multicolumn{2}{c}{$\begin{array}{c}\text { Career } \\
\text { Expectations }\end{array}$} \\
Kendall's & Research and & Correlation &,- 018 \\
tau_b & $\begin{array}{l}\text { Technological Sub- } \\
\text { competence }\end{array}$ & Coefficent &, 619 \\
& & Sig. (2-tailed) & 448 \\
\hline
\end{tabular}

A p-value of ,619 was found. Even though a correlation coefficient of -,018 indicates that two variables are related in a negative linear sense, the variables are uncorrelated. The null hypothesis is rejected.

Table 8. Relationship between Strategic Sub-competence and Career Expectations

\begin{tabular}{|c|c|c|c|}
\hline \multicolumn{4}{|c|}{ Strategic Sub-competence correlations } \\
\hline \multirow{4}{*}{$\begin{array}{l}\text { Kendall's } \\
\text { tau_b }\end{array}$} & \multirow{4}{*}{$\begin{array}{l}\text { Strategic sub- } \\
\text { competence }\end{array}$} & & $\begin{array}{c}\text { Career } \\
\text { Expectations }\end{array}$ \\
\hline & & $\begin{array}{l}\text { Correlation } \\
\text { Coefficent }\end{array}$ &,- 094 \\
\hline & & Sig. (2-tailed) &, 010 \\
\hline & & $\mathrm{N}$ & 446 \\
\hline
\end{tabular}

A p-value of ,010 was found. A correlation coefficient of -,094 indicates that two variables are related in a negative linear sense and the null hypothesis is accepted.

Table 9. Relationship between Knowledge about Translation sub-competence and Career Expectations

\begin{tabular}{lllr}
\hline \multicolumn{2}{c}{ Knowledge about Translation sub-competence correlations } \\
\hline \multirow{2}{*}{ Kendall's tau_b } & $\begin{array}{c}\text { Career } \\
\text { Knowledge about } \\
\text { Translation sub- } \\
\text { competence }\end{array}$ & $\begin{array}{l}\text { Correlation } \\
\text { Coefficent }\end{array}$ &,- 114 \\
& Sig. (2-tailed) &, 002 \\
& $\mathrm{~N}$ & 448 \\
\hline
\end{tabular}

A p-value of ,002 was found. A correlation coefficient of -,114 indicates that two variables are related in a negative linear sense and the null hypothesis is accepted. 
Table 10. Relationship between Translation Service Provision Sub-competence and Career Expectations

Translation Service Provision Sub-competence correlations

\begin{tabular}{|c|c|c|c|}
\hline \multirow{4}{*}{ Kendall's tau_b } & \multirow{4}{*}{$\begin{array}{l}\text { Translation Service } \\
\text { Provision Sub- } \\
\text { competence }\end{array}$} & & $\begin{array}{c}\text { Career } \\
\text { Expectations }\end{array}$ \\
\hline & & $\begin{array}{l}\text { Correlation } \\
\text { Coefficent }\end{array}$ &,- 073 \\
\hline & & Sig. (2-tailed) & 043 \\
\hline & & $\mathrm{N}$ & 440 \\
\hline
\end{tabular}

A p-value of ,043 was found. A correlation coefficient of -,073 indicates that two variables are related in a negative linear sense and the null hypothesis is accepted.

\section{Discussion \& Conclusion}

Of all the sub-competencies, two sub-competencies seem to be uncorrelated. The rest is correlated in a negative linear sense. This indicates that there is a relationship between the career expectations of the participants and their acquisition of translation competence. The relationship seems to be correlated in a negative way. This can be due to the fact that the sub-competencies in these models of translation competence do not cover any sub-competencies relating to the translation business as a market such as setting up a translation company and managing the business. The participants are not very much interested in setting up a translation business that account for 3,3\%. Most program designs at the department of translation and interpreting at university are competence-based. Unless courses relating to translation business are incorporated into the program designs, this dimension will remain unsolved. Therefore, there is a need to change the focus from translation competence to translator's competence from an organizational perspective. Kiraly also considers translator's competence to be a priority. He states that a translator is responsible for activities beyond the job description that translation competence requires them to fulfill (Kiraly, 2003:12-13). Bell mentions a concept of Translator Communicative Competence by which he emphasizes the concept of translator's competence (Bell, 1991:42). Bell deals with the knowledge and skills that a translator needs to have in a manner that is socially acceptable. Baker and Maier state that the responsibility of translators and interpreters extends beyond clients to include the wider community to which they belong and they need to develop an awareness of its impact on society (Baker and Maier, 2011:1). We must design programmes for the departments of translation and interpreting at university level in such a way to include the needed sub-competencies thereof. What kind of sub-competencies can we mention? The nature and management of businesses may be helpful.

Translation is a business and it is a service as a market offering in the translation market. It has to be managed in an effective and efficient way. Management is the intergrating force in all organized activity and is applicable to every organization. So, it is universal. It is goal-oriented as it aims to achieve a result. It has a structure because tasks must be identified. It is social since it is a process carried out through people. Management is effective as it gets close to the goal and efficient if it has used less resources. Daft defines management as (Daft, 1997:8):

"Management is the attainment of organizational goals in an effective and efficient way through planning, organizing, leading, and controlling organizational resources."

There are three critical skills in management: technical, human (interpersonal), and conceptual (Katz, 1974). Technical skills are the job-specific knowledge and techniques needed to proficiently perform work tasks. Human (interpersonal) skills involve the ability to work well with other people both individually and in a group. Because there is an element of dealing with people, these skills are equally important to all levels of management. It is important to know how to communicate, motivate, lead, and inspire enthusiasm and trust. Finally, conceptual skills are the skills used to think and to conceptualize about abstract and complex situations. Using these skills, one can see the organization as a whole, understand the relationships among various sub-units, and visualize how the business (or the service as a market offering) fits into its broader environment (Robbins and Coulter, 2012:13-14).

A translation company/project can be considered to be a goal-oriented, structured, and social process. Therefore, such sub-competencies as knowledge of marketing shown in the matrix of translation competence are possible to be placed under the managerial skills.

Translation competence is the technical aspect of the translation business. A model of translator's competence versus translation competence is an umbrella term which must cover all the skills. We need to look at the technical skills of a translator and an interpreter more closely i.e. the core competencies that play a part in order to translate. Then, we can make use of these technical skills as the foundations upon which we can build the concept of translator's competence. Translation competence which we call technical skills mainly draws on the model put forward by the PACTE research group and TransComp research project.

This dimension in the translation phenomenon makes two processes noticeable in the production of the target text: the translation process of a translator and the translation process of a translation company. These two processes are different in that they require different skills and knowledge from each other. The latter covers all activities from the negotiation of the translation project to the production of a target text, and to the customer relations management. The former falls within the scope of the translation process of the translation company. This is where a holistic approach 
needs to be embraced. As the job descriptions in a translation company begin to be identified, so a translator's responsibility and their relationship with the other jobs will be much clearer. It will be more effective to make sure that program designs at the department of Translation Studies be improved to include the concept of competence when approached from an organizational viewpoint. In Table 13, a model of translator's competence is proposed.

Translation competence is one of the constituents that the translator's competence is made up of. Conceptual skills and interpersonal skills are the other constituents. These three skills constitute the model of translator's competence. Translation competence makes it possible for a translator to fulfill their job description in a translation company and can be considered as a technical skill.

Table 11. A Model of Translator's Competence

Translator's Competence

\begin{tabular}{lll}
\hline \multicolumn{1}{c}{ Technical Skills } & \multicolumn{1}{c}{ Conceptual Skills } & \multicolumn{1}{c}{ Interpersonal Skills } \\
Bilingual sub-competence & Planning & Leading \\
Cultural sub-competence & Organizing & \\
Textual sub-competence & Controlling &
\end{tabular}

Thematic sub-competence

Strategic sub-competence

Research sub-competence

Knowledge about Translation sub-

competence

Instrumental sub-competence

A translator needs to use resources effectively and efficiently through other people in order to attain organizational/project goals. Therefore, they use the functions of management such as planning, organizing, leading and controlling. Of these, conceptual skills consist of planning, organing and controlling. It has to do with the skill to see an organization/a project as a whole made up of constituents and to manage it. Interpersonal skills are the skills to work with other people. Only by using this skill is it possible to understand, communicate with, lead people and resolve conflicts among them. Leading as a management function is categorised in this part (Mirze, 2010:40-45). If the interpersonal sub-competence lacks, but the other sub-competencies exist, success can fail. However, this subcompetence alone can not guarantee success (Hitt et. al., 2009: 41).

Management requires a translator to relate their job description to the translation project, organization, sector and general environment. The organizational environment is the internal environment of the organization and covers the other employees and organizational culture. The sectoral and general environment is the external environment and the sectoral one represents rivals, suppliers and customers while the general environment covers political, economic, technological and legal conditions.

There is a need for a translator to fulfill tasks beyond their own job description, thus leading to a need for a new model of competence, which is translator's competence as depicted above. Professionalization makes it necessary for conceptual and interpersonal skills to constitute the model of translator's competence alongside with technical skills i.e. translation competence. This could also mean a solution to the overlapping and contradiction existing among the subcompetencies in the matrix of translation competence. In addition, curricula at the department of Translation and Interpreting can be designed to include the sub-competencies indicated in the proposed model of translator's competence.

\section{References}

Albir, A. H. (2010). Competence, in Handbook of Translation Studies ed. by Yves Gambier et. al., Amsterdem/Philadelphia: John Benjamins Publishing Company,2010

Baker, M. and Maier, C. (2011). Ethics in Interpreter \& Translator Training: Critical Perspectives. in The Interpreter and Translator Trainer 5(1), 1-14

Bell, R. T. (1991). Translation and Translating: Theory and Practice. London and New York: Longman

CEN (2006). EN-15038 Translation Services -Service Requirements. Brussels

DeSeCo (2001). Definition and Selection of Competencies:Theoratical and Conceptual Foundations, Background paper, (çevirimiçi, http://www.oecd.org/education/highereducationandadultlearning/41529556.pdf). 
EMT expert group (2009). Competences for Professional Translator, Experts in Multilingual and Multimedia Communication. Brussels. (Access http://ec.europa.eu/emt, 13 February 2012)

Eser, O. (2013). Çeviri Ĕ̆itiminde Edinç Kavramının Değerlendirilmesi, PhD, Istnabul University.

Eymen, U. E. (2007). SPSS 15.0 Veri Analiz Yöntemleri, İstatistik Merkezi Yayın No: 1, 2007, Retrieved from http://www.istatistikmerkezi.com, 3 November 2012.

Göpferich, S. (2009). Towards a Model of Translation Competence and its Acquisition: The Longitudinal Study of TransComp, Behind the Mind: Methods, Models, and Results in Translation Process Research, ed. by Sussanne Göpferich, Arnt Lykke Jakobsen, and Inger M. Mees, Denmark, Samfundslitteratur, s.12-39.

Hitt, M. A., Black, Stewart, J., and Porter, L. W. (2009). Management. 2nd. Edition, New Jersey: Pearson Education, Inc.

Jonnaert, P. et. al. (2006). Revisiting the Concept of Competence as an Organizing principle for Programs of Study:FromCompetence to Competent Action, Geneva: International Bureau of Education, IBE/UNESCO.

Katz, R. L. (1974). Skills of an Effective Administrator, Harvard Business Review, September/ October, pp. 90-102.

Kiraly, D. C. (2003). From Instruction to Collaborative Condruction: A Passing Fad or the Promise of a Paradigm Shift in Translator Education. Rethinking Translation Pedagogy. ed. by Brian James Baerand Geoffrey S. Coby, Volume XII, Amsterdam and Philadelphia: John Benjamins Publishing Company, 2003, pp. 3-27.

Mirze, S. K. (2010). İşletme. İstanbul: Literatür

Neubert, A. (2000). Competence in Language, in Languages, and in Translation. Developing Translation Competence. Ed. by Schäffner, Christina and Adab Beverly, Amsterdam and Philadelphia, John Benjamins, 2000, pp:3-18.

PACTE Group (2000). Acquiring Translation Competence: Hypotheses and Methodological Problems in a Reseach Project. Investigating Translation. ed. by A. Beeby, D. Ensinger, M. Presas, Amsterdam, John Benjamins, pp.99-106.

PACTE Group (2003). Building a Translation Competence Model. Triangulating Translation: Perspectives in Process Oriented Reseach. ed. by E.Alves, Amsterdam, John Benjamins, s.43-66.

PACTE Group (2005). Investigating Translation Competence: Conceptual and Methodological Issues. Meta, 50 (2), 609-619.

PACTE Group (2011). Results of the Validation of the PACTE Translation Competence Model: Translation Project and Dynamic Translation Index. Cognitive Explorations of Translation, Ed. by Sharon O'brien, London and New York, Continuum International Publishing Group, s.30-53.

Rychen, D. S. (2003). Investing in Competencies - but which competencies and for what? A contribution to the ANCLI/AEA Conference on Assessment Challenges for Democratic Society (Conference paper). Lyon: OECD Project DeSeCo,.

Schäffner, C. (2000). Running before Walking? Designing a Translation Programme at Undergraduate Level. Developing Translation Competence. ed. by Schäffner, Christina and Adab Beverly, Amsterdam and Philadelphia, John Benjamins, pp:143-156.

Schneckenberg, D. and Johannes W. (2006). "Understanding the Concept of Ecompetence for Academic Staff”, in The Challenge of eCompetence in Academic Staff Development, (Eds.) Mac Labhrainn, I., McDonald Legg, C., Schneckenberg, D., Wildt, J., Galway: CELT, (Access http://www.ecompetence.info/uploads/media/ch3.pdf, erişim, 24 Eylül 2012)

Weinert, F. E. (1999). Concept of Competence, Munich, Germany:Max Plank Institute for Psychological research Yazıcı, M. (2007). Yazılı Çeviri Edinci. İstanbul: MULTILINGUAL 


\section{Scale of Translation Competence}

1 My mother tongue is at an advanced level.

2 I can manage a thematic database

3 I regard myself as a cultural expert as a result of the education I have received.

4 My 1st foreign language is at an advanced level.

5 I can archive documents.

\begin{tabular}{l|l}
6 & I can assess the translation-oriented problems of a text.
\end{tabular}

7 My 2nd foreign language is is at an intermediate level.

8 I am aware of the contemporary translation theories.

9 I know how to use translation tools and software effectively.

10 I can relate translation criticism to translation theories.

11 I can relate translation decisions to a given macro-strategy.

12 I know how to justify my translation choices and decisions.

13 Translation theories play an important role in setting up translation strategies.

14 Translation theories make me feel self-confident.

15 I can use the translation theories appropriate to the translation project.

16 I can put translation priorities in a hierarchical order of sub competencies.

17 I know how to clarify the requirements and purposes of the translation stakeholders.

18 I can plan a translation project.

19 I can manage a translation project.

20 I can detect translation problems and find solutions.

21 I make use of translation theories in spotting tranlation problems and sorting them out.

22 I know the possibilities and limits of technology in solving translation problems.

23 I can set up a functional translation strategy.

I know how to search for appropriate information about th thematic aspects of a text during the 24 translation process.

\begin{tabular}{|l|l}
25 & I can use the languages in order to translate functionally.
\end{tabular}

26 I can relate the sub-competencies of translation to each other.

27 I can develop a macro-strategy in translation.

28 I am aware of the social dimension of translation.

29 I know about the translation quality standards like EN-15038.

30 I can produce a functional target text appropriate to the target audience.

31 I can translate in one of the specialist fields like law, economics or medicine.

32 My bi-lingual competence covers the source and target cultures.

33 My intercultural competence has an influence on my translation strategies and decisions.

I can identify necessary information and documents to understand the source text and produce 34 the target text.

I can recognize the macro-structure and the meaning of a text in the source language and the

35 target language.

36 I know how to draft rapidly and well.

37 I can identify values and references proper to the cultures.

I know how to recognise function and meaning about the social, economical and political

38 history of the source and the target cultures.

39 I can set up a translation strategy appropriate to the text-types and functions.

40 I know about the text-types including specialist texts in the source and the target language.

41 I can assess myself.

\begin{tabular}{l|l|l|l|l|}
1 & 2 & 3 & 4 & 5 \\
\hline 1 & 2 & 3 & 4 & 5 \\
\hline
\end{tabular}

\begin{tabular}{l|l|l|l|l|}
1 & 2 & 3 & 4 & 5 \\
\hline 1 & 2 & 3 & 4 & 5 \\
\hline
\end{tabular}

\begin{tabular}{l|l|l|l|l|}
1 & 2 & 3 & 4 & 5 \\
\hline
\end{tabular}

\begin{tabular}{|l|l|l|l|l|}
1 & 2 & 3 & 4 & 5 \\
\hline 1 & 2 & 3 & 4 & 5
\end{tabular}

\begin{tabular}{|l|l|l|l|l|}
1 & 2 & 3 & 4 & 5 \\
\hline 1 & 2 & 3 & 4 & 5 \\
\hline 1 & 2 & 3 & 4 & 5
\end{tabular}

\begin{tabular}{|l|l|l|l|l|}
1 & 2 & 3 & 4 & 5 \\
\hline 1 & 2 & 3 & 4 & 5 \\
1 & 2 & 3 & 4 & 5
\end{tabular}

\begin{tabular}{|l|l|l|l|l|}
1 & 2 & 3 & 4 & 5 \\
\hline 1 & 2 & 3 & 4 & 5
\end{tabular}

\begin{tabular}{|l|l|l|l|l|}
1 & 2 & 3 & 4 & 5 \\
\hline 1 & 2 & 3 & 4 & 5 \\
\hline
\end{tabular}

\begin{tabular}{|l|l|l|l|l|}
1 & 2 & 3 & 4 & 5 \\
\hline 1 & 2 & 3 & 4 & 5 \\
\hline 1 & 2 & 3 & 4 & 5 \\
\hline
\end{tabular}

\begin{tabular}{|l|l|l|l|l|l|}
1 & 2 & 3 & 4 & 5 \\
\hline 1 & 2 & 3 & 4 & 5 \\
\hline 1 & 2 & 3 & 4 & 5 \\
\hline
\end{tabular}

\begin{tabular}{|l|l|l|l|l|}
1 & 2 & 3 & 4 & 5 \\
\hline 1 & 2 & 3 & 4 & 5 \\
\hline
\end{tabular}

\begin{tabular}{|l|l|l|l|l|}
1 & 2 & 3 & 4 & 5 \\
\hline 1 & 2 & 3 & 4 & 5 \\
\hline 1 & 2 & 3 & 4 & 5 \\
\hline
\end{tabular}

\begin{tabular}{|l|l|l|l|l|}
1 & 2 & 3 & 4 & 5 \\
\hline 1 & 2 & 3 & 4 & 5
\end{tabular}

\begin{tabular}{|l|l|l|l|l|}
1 & 2 & 3 & 4 & 5 \\
\hline 1 & 2 & 3 & 4 & 5 \\
\hline 1 & 2 & 3 & 4 & 5 \\
\hline 1 & 2 & 3 & 4 & 5 \\
\hline 1 & 2 & 3 & 4 & 5 \\
\hline
\end{tabular}




\begin{tabular}{|c|c|c|c|c|c|c|}
\hline 42 & I know how to negotiate with the client. & 1 & 2 & 3 & 4 & 5 \\
\hline 43 & I know how to offer a translation appropriate to the client's request. & 1 & 2 & 3 & 4 & 5 \\
\hline 44 & I know how to follow market requirements and job profiles. & 1 & 2 & 3 & 4 & 5 \\
\hline 45 & I know how to proofread and revise a translation. & 1 & 2 & 3 & 4 & 5 \\
\hline 46 & I know how to specify and calculate the services offered and their added value. & 1 & 2 & 3 & 4 & 5 \\
\hline 47 & I know how to work in a team. & 1 & 2 & 3 & 4 & 5 \\
\hline 48 & I can use the meta-language. & 1 & 2 & 3 & 4 & 5 \\
\hline 49 & I can manage a database. & 1 & 2 & 3 & 4 & 5 \\
\hline 50 & I know how to plan and manage one's time, stress, work and budget. & 1 & 2 & 3 & 4 & 5 \\
\hline
\end{tabular}

Appendix 2 - Reference to the Scale of Translation Competence

\begin{tabular}{|c|c|c|c|c|c|c|}
\hline \multicolumn{2}{|r|}{$\begin{array}{c}\text { Scale of } \\
\text { Translation Competence } \\
\text { (for Referential Purposes) }\end{array}$} & 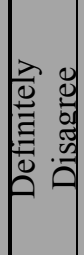 & 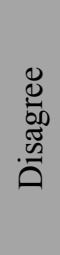 & 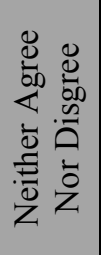 & 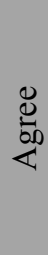 & 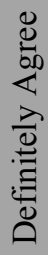 \\
\hline \multicolumn{2}{|c|}{ Bi-lingual sub-competence } & 1 & 2 & 3 & 4 & 5 \\
\hline 1 & My mother tongue is at an advanced level. & & & & & \\
\hline 2 & My 1st foreign language is at an advanced level. & & & & & \\
\hline 3 & My 2nd foreign language is is at an intermediate level. & & & & & \\
\hline 4 & I can use the languages in order to translate functionally. & & & & & \\
\hline 5 & My bi-lingual competence covers the source and target cultures. & & & & & \\
\hline \multicolumn{2}{|c|}{ Cultural sub-competence } & 1 & 2 & 3 & 4 & 5 \\
\hline 6 & $\begin{array}{l}\text { I know how to recognise function and meaning about the social, economical and political history } \\
\text { of the source and the target cultures. }\end{array}$ & & & & & \\
\hline 7 & I can identify values and references proper to the cultures. & & & & & \\
\hline 8 & My intercultural competence has an influence on my translation strategies and decisions. & & & & & \\
\hline 9 & I regard myself as a cultural expert as a result of the education I have received. & & & & & \\
\hline \multicolumn{2}{|r|}{ Domain/Thematic sub-competence } & 1 & 2 & 3 & 4 & 5 \\
\hline 10 & I can translate in one of the specialist fields like law, economics or medicine. & & & & & \\
\hline 11 & $\begin{array}{l}\text { I know how to search for appropriate information about th thematic aspects of a text during the } \\
\text { translation process. }\end{array}$ & & & & & \\
\hline 12 & I can manage a thematic database. & & & & & \\
\hline \multicolumn{2}{|r|}{ Textual sub-competence } & 1 & 2 & 3 & 4 & 5 \\
\hline 13 & I can produce a functional target text appropriate to the target audience. & & & & & \\
\hline 14 & I know about the text-types including specialist texts in the source and the target language. & & & & & \\
\hline 15 & I can set up a translation strategy appropriate to the text-types and functions. & & & & & \\
\hline 16 & $\begin{array}{l}\text { I can recognize the macro-structure and the meaning of a text in the source language and the target } \\
\text { language. }\end{array}$ & & & & & \\
\hline 17 & I can assess the translation-oriented problems of a text. & & & & & \\
\hline 18 & I know how to draft rapidly and well. & & & & & \\
\hline \multicolumn{2}{|r|}{ Research and technological sub-competence } & 1 & 2 & 3 & 4 & 5 \\
\hline 19 & $\begin{array}{l}\text { I can identify necessary information and documents to understand the source text and produce the } \\
\text { target text. }\end{array}$ & & & & & \\
\hline 20 & I know how to use translation tools and software effectively. & & & & & \\
\hline 21 & I can archive documents. & & & & & \\
\hline 22 & I can manage a database. & & & & & \\
\hline 23 & I know the possibilities and limits of technology in solving translation problems. & & & & & \\
\hline \multicolumn{2}{|r|}{ Strategic sub-competence } & 1 & 2 & 3 & 4 & 5 \\
\hline 24 & I can set up a functional translation strategy. & & & & & \\
\hline
\end{tabular}


IJCLTS 3 (1):4-15, 2015

25 I can detect translation problems and find solutions.

26 I can plan a translation project.

27 I can manage a translation project.

28 I can relate the sub-competencies of translation to each other.

29 I can put translation priorities in a hierarchical order of sub competencies.

30 I can develop a macro-strategy in translation.

31 I can relate translation decisions to a given macro-strategy.

\section{Knowledge about tranlation sub-competence}

\begin{tabular}{l|l}
32 & I am aware of the contemporary translation theories.
\end{tabular}

33 I can use the translation theories appropriate to the translation project.

34 Translation theories play an important role in setting up translation strategies.

35 Translation theories make me feel self-confident.

36 I make use of translation theories in spotting tranlation problems and sorting them out.

37 I can use the meta-language.

38 I can relate translation criticism to translation theories.

\section{Translation service provision sub-competence}

39 I am aware of the social dimension of translation.

40 I know how to follow market requirements and job profiles.

41 I know how to negotiate with the client.

42 I know how to clarify the requirements and purposes of the translation stakeholders.

43 I know how to plan and manage one's time, stress, work and budget.

44 I know how to specify and calculate the services offered and their added value.

45 I know about the translation quality standards like EN-15038.

46 I know how to offer a translation appropriate to the client's request.

47 I know how to justify my translation choices and decisions.

48 I can assess myself.

49 I know how to proofread and revise a translation.

50 I know how to work in a team. 